\title{
Customers' satisfaction about prehospital emergency medical services in Lorestan, Iran
}

Heshmatolah Heydari ${ }^{1}$, Aziz Kamran ${ }^{2}$, Morad Esmaiel Zali ${ }^{3}$, Nasser Novinmehr ${ }^{4}$, Mehdi Safari ${ }^{5}$

${ }^{1}$ Ph.D. of Community Health Nursing, Assistant Professor, Department of Community Health Nursing, Faculty of Medicine and Health Sciences, Lorestan University of Medical Sciences, Khorramabad, Iran

${ }^{2} \mathrm{Ph}$.D. of Education and Health Promotion, Assistant Professor, Department of Public Health, Faculty of Medicine and Health Sciences, Ardabil University of Medical Sciences, Khalkhal, Iran

${ }^{3}$ Ph.D. of Health Care Services Management, School of Public Health and Institute of Public Health Research, Tehran University of Medical Sciences, Tehran, Iran

${ }^{4}$ Ph.D. Candidate in Nursing, Department of Mental Health Nursing, School of Nursing and Midwifery, Tehran University of Medical Sciences (TUMS), Tehran, Iran

${ }^{5}$ M.Sc. of Biostatistics, Department of Public Health, Young Researcher and Elite Club, Yadegar-e-emam Khomini (RAH)-Shahre- rey Branch, Islamic Azad University, Tehran, Iran

\section{Type of article: Original}

\begin{abstract}
Introduction: Patient's satisfaction with health care in ambulance services is an important quality indicator and a helpful tool for managers of prehospital emergency services. This study aimed to measure patient satisfaction with health provided by prehospital emergency medical services (EMS) in Lorestan, Iran.

Methods: This cross-sectional study was conducted on patients $(n=450)$ transferred by EMS to hospitals of Lorestan University of Medical Sciences in a two-year period (2013-2014). Data collection was performed by patient questionnaire, which is a standard LKFR tool. Validity and reliability of the instrument was confirmed by scientific method. Collected data were analyzed by SPSS Version 19. Descriptive and inferential statistics such as Chi-square, paired-samples t-test, independent-samples t-test, ANOVA, Pearson's product-moment correlation coefficient, and Fisher's exact test were used.

Results: One hundred ninety-two (42.8\%) and 257 (57.2\%) patients were female and male, respectively (mean: 41 years, r: 37-83). Patient satisfaction of the dispatcher was good, and satisfaction level in regards to the technicians' performance, physical situation, and facilities inside the ambulance was moderate. The Wilcoxon test did not show any significant difference between pain severity before and after arriving EMS in the cardiac and respiratory patients $(\mathrm{p}=0.691)$, but severity of pain in orthopedic patients after arriving EMS was decreased $(\mathrm{p}=0.001)$. Cardiac and respiratory patients had low satisfaction of EMS, and the Chi-square test was significant $(\mathrm{p}=0.001)$. Orthopedic patients had the most satisfaction of EMS.

Conclusion: Generally, patients' satisfaction of EMS was low. Satisfaction with pain relief in orthopedic patients was better than pain relief in cardiac and respiratory patients. It is recommended to take necessary actions to improve the level of patient satisfaction of EMS.
\end{abstract}

Keywords: Patient satisfaction, Prehospital, Emergency, Medical services

\section{Introduction}

Patient satisfaction is a widely used concept; today, it is considered one of the crucial dimensions of clinical governance (1). Satisfaction has a critical role in health maintenance and prevention of diseases (2) and is considered an indicator for evaluating organizational performance (3). Satisfaction is affected by many factors such as socioeconomic status, physical and mental state, literacy, quality of the medical care, and patient recovery (4).

\section{Corresponding author:}

Nasser Novinmehr, Department of Mental Health Nursing, School of Nursing and Midwifery, Tehran University of Medical Sciences (TUMS), Nosrat St., Tohid Sq., 1419733171, Tehran, Iran.

Tel.: +98.9183130828; Fax: +98.8138278330. Email: nvnmhr@yahoo.com

Received: March 18, 2016, Accepted: November 22, 2016, Published: March 2017

iThenticate screening: November 11, 2016, English editing: January 21, 2017, Quality control: February 12, 2017

(C) 2017 The Authors. This is an open access article under the terms of the Creative Commons Attribution-NonCommercialNoDerivs License, which permits use and distribution in any medium, provided the original work is properly cited, the use is non-commercial and no modifications or adaptations are made. 
Providing health services for the entire population in Iran is the responsibility of the ministry of health; in the province level, it is done by the universities of medical sciences in that region. Emergency medical services (EMS), known as 115 , in the provinces level is led by the provincial university of medical sciences and has a critical role in delivery of the prehospital services in emergency situations such as traffic accidents, cardiopulmonary diseases, and poisonings (5). Prehospital emergency services are in the forefront of health care systems in emergency situations (6). About $80 \%-85 \%$ of assignments in emergency medical services in Iran are related to transfer of patients having acute problems to a health center $(8,7)$. A number of deaths occur in the prehospital phase in developing countries (9), which can be reduced by better and faster prehospital emergency care. Some studies indicate a moderate level of customer satisfaction with prehospital emergency care in Iran $(10,11)$. Another study showed a good level of satisfaction with ambulance appearance, relaxation, and security at the time of ambulance arrival and access to technicians (12), but a defect was observed in the quantity of human resources and equipment (13). Similarly, researchers in other countries reported similar findings (14-16). Quality of the emergency services should be evaluated by governmental organizations and insurance companies (17). Although the customers' feedback can improve the quality of services, there was no comprehensive report about this topic in Iran. The aim of this study is to determine the level of patients' satisfaction with emergency medical services in Lorestan University of Medical Sciences.

\section{Material and Methods}

This study was conducted as a research project approved by the Research Center of Lorestan University of Medical Sciences, Khorramabad, Iran (ref. no.: 1783). In this cross-sectional study, 450 patients with cardiac, respiratory, or orthopedic diseases, transferred by EMS to teaching hospitals of Lorestan University of Medical Sciences in a twoyear period (2013-2014) were included. The method of selection was continuous. Sample size was estimated to be 400 at $95 \%$ confidence, satisfaction rate of 0.5 , and SD of 0.05 . One hundred fifty patients were selected for each diagnosis of the cardiac, respiratory, or orthopedic diseases by an emergency physician. Inclusion criteria included age between 15 and 70 years, literate, full consciousness, and consent to participate in the study. Data were collected at admission departments of Lorestan hospitals, and patients were selected who were dispatched to the hospital in the past 24 hours by EMS and met the inclusion criteria. An LKFR tool was used for data collection (19). This tool consists of five separate parts. First part contains demographic information of cases, technicians, and the type of ambulance. The second part contains eight questions about the satisfaction with service delivery. These questions were designed using 5-point Likert scales; the total scores in this part were 8-40. Scores between 8 and 11 indicate that the level of satisfaction was low; scores between 12 and 29 indicate that the level of satisfaction was moderate; scores between 30 and 40 indicate that the level of satisfaction was high. The third part contains six questions using a 5-point Likert scale about the performance of an EMS technician; the total scores in this part were between 6 and 30. Scores between 6 and 14 indicate that the level of satisfaction was low; scores between 15 and 23 indicate that the level of satisfaction was moderate; scores between 24 and 30 indicate that the level of satisfaction was high. In the fourth part, the physical comfort and equipment inside the ambulance was assessed; this part includes seven questions using 5-point Likert scales. The total scores in this part were 7-49. Scores between 7 and 21 indicate that the level of satisfaction was low; scores between 22 and 36 indicate that the level of satisfaction was moderate; scores between 37 and 49 indicate that the level of satisfaction was high. Questions are rated on a Likert scale from 1 to 5; a score of 1 was defined as dissatisfaction, and a score 5 was defined as full satisfaction of the services. Total scores earned by cases from these four parts of the questionnaire were 21 to 105 . Scores between 21 and 49 indicate that the level of satisfaction was low; scores between 50 and 78 indicate that the level of satisfaction was moderate, scores between 79 and 105 indicate that the level of satisfaction was high. The fifth, sixth, and seventh parts of questionnaire were about satisfaction level of cardiac, respiratory, and orthopedic patients before and after arrival of EMS; these parts of the questionnaire were designed on a visual analog scale and determined the subjective feelings of patients about their pain and discomfort and were rated from 0 to 16 scores. Scores between 0 and 5 indicate slight pain; scores between 5 and 10 indicate moderate pain; scores between 10 and 16 indicate severe pain. Validity of the instrument was confirmed by content validity, and its reliability was confirmed by internal consistency and Quadric Richardson test. Data were analyzed by SPSS Version 19 using descriptive and inferential statistic such as Chi-square, paired-samples t-test, independent-samples t-test, ANOVA, Pearson's product-moment correlation coefficient, and Fisher's exact test. Written and informed consent was obtained from all patients.

\section{Results}

The mean age of the total sample was 41 years, ranging from 37 to $83 ; 57.2 \%$ of the sample were male and $42.8 \%$ were female. Most of the subjects were literate (63.8\%). Most of the emergency medical technicians (53.8\%) had working experience for about 15-20 years, and most of them (28.4\%) were temporary employees. The mean waiting 
time for EMS arrival was $7.4 \pm 4.2$ minutes. Most of the subjects $(60.02 \%)$ expressed that the emergency medical dispatchers did not introduced themselves; $98.66 \%$ of them were assessed by the dispatcher, and $96.88 \%$ of subjects were guided by the dispatcher until arriving at EMS; $82 \%$ of subjects mentioned that they were not assessed by the physician in the EMS call center. Overall, the level of satisfaction with the dispatcher was good (31 \pm 8.47$)$. Most of the subjects $(66.44 \%)$ mentioned that they were treated with courtesy and respect; $85.33 \%$ of patients were satisfied with the technician's uniform, and $40.22 \%$ of the subjects were moderately satisfied with the technician's selfintroduction. The overall level of satisfaction with the performance of technicians was moderate (18.6 \pm 9.24$)$. Most of the subjects $(81.33 \%)$ mentioned that the inside of the ambulance was moderately clean, and $79.77 \%$ of them assessed its air-conditioning as moderate. Overall level of satisfaction about the physical comfort and equipment inside the ambulance was moderate. Among 150 cardiac patients, $52 \%$ were female; $32.2 \%$ of females and $12.5 \%$ of males were dissatisfied with the EMS, and the Chi-square test showed a significant correlation $(p<0.001)$ between the gender and satisfaction level; $52 \%$ of cardiac patients were literate, and the Chi-square test showed a significant correlation between literacy and satisfaction level $(p<0.001)$. Most of the cardiac patients' satisfaction was related to the technicians with a B.Sc. nursing degree, and the least satisfaction was related to technicians with a diploma; this correlation was significant in the Chi-square test $(\mathrm{p}<0.001) ; 66.6 \%$ of the respiratory patients were female, and $29 / 7 \%$ of them showed the low satisfaction with EMS; the Chi-square test was significant $(p<0.001)$ for correlation between gender and satisfaction level. A significant correlation was demonstrated between age and satisfaction level in the Chi-square test $(\mathrm{p}<0.001)$. Subjects with higher age were more satisfied, and an exact Fisher test showed correlation between age and satisfaction level $(\mathrm{p}<0.004)$. The subjects expressed the most satisfaction with the technicians who had a BSc in nursing and 5-10 years of experience $(\mathrm{p}<0.001)$ and the technicians with official employment on a Chi-square test $(\mathrm{p}<0.002)$. Of 150 orthopedic patients, $126(84 \%)$ were male and expressed the most satisfaction with EMS. Exact Fisher test showed a significant correlation between satisfaction and sex $(\mathrm{p}<0.001)$. Chi-square test showed the correlation between satisfaction and literacy level of the orthopedic patients $(\mathrm{p}<0.002)$. Orthopedic patients with a diploma expressed the most satisfaction level with EMS. The subjects expressed the most satisfaction with the technicians with a BSc nursing degree, length of employment 25-30 years $(p<0.001)$. The subjects expressed the most satisfaction with the technicians with official employment $(p<0.002)$. The Wilcoxon test showed no significant difference in pain intensity in the cardiac and respiratory patients, before and after EMS arrival $(\mathrm{p}<0.716)$, but in the orthopedic patients this difference was significant $(\mathrm{p}<0.001)($ Table 1$)$.

Table 1. Pain intensity in the patients, before and after EMS arrival

\begin{tabular}{|c|c|c|c|c|c|c|}
\hline \multirow{3}{*}{\multicolumn{2}{|c|}{ Pain Intensity }} & \multicolumn{5}{|c|}{ Presence of EMS } \\
\hline & & \multicolumn{2}{|c|}{ Before Presence EMS } & \multicolumn{2}{|c|}{ After Presence EMS } & \multirow{2}{*}{$\begin{array}{l}\mathrm{p} \text {-value } \\
0.691\end{array}$} \\
\hline & & $\mathrm{n}$ & $\%$ & $\mathrm{n}$ & $\%$ & \\
\hline \multirow[t]{6}{*}{ Cardiac patients } & Slight & 2 & 1.3 & 2 & 3 & \\
\hline & Moderate & 43 & 28.7 & 31.3 & 47 & \\
\hline & Severe & 105 & 70 & 66.7 & 100 & \\
\hline & Sum & 150 & 100 & 100 & 150 & \\
\hline & \multirow[t]{2}{*}{ Severity of Pain } & Mean & SD & SD & Mean & \\
\hline & & 2.68 & 0.398 & 0.498 & 2.70 & \\
\hline \multirow[t]{6}{*}{ Respiratory patients } & Slight & 2 & 1.3 & 2 & 1.3 & \multirow[t]{6}{*}{0.716} \\
\hline & Moderate & 50 & 33.3 & 59 & 39.3 & \\
\hline & Severe & 98 & 65.3 & 89 & 59.3 & \\
\hline & Sum & 150 & 100 & 150 & 100 & \\
\hline & \multirow[t]{2}{*}{ Severity of Pain } & Mean & SD & SD & Mean & \\
\hline & & 2.64 & 0.508 & 2.62 & 0.513 & \\
\hline \multirow{6}{*}{ Orthopedic patients } & Slight & 0 & 0 & 37 & 24.7 & \multirow[t]{6}{*}{0.001} \\
\hline & Moderate & 17 & 11.3 & 45 & 30 & \\
\hline & Severe & 133 & 88.7 & 68 & 45.3 & \\
\hline & Sum & 150 & 100 & 150 & 100 & \\
\hline & \multirow[t]{2}{*}{ Severity of Pain } & Mean & SD & SD & Mean & \\
\hline & & 0.813 & 2.20 & 0.318 & 2.88 & \\
\hline
\end{tabular}

\section{Discussion}

As the findings show, patients' satisfaction with the inside of an ambulance and the technician's performance was moderate; the satisfaction with the dispatcher was good. Satisfaction with pain relief in the orthopedic patients was 
better than pain relief in the cardiac and respiratory patients. A 2012 study by Mozafari showed that patients' satisfaction with EMS was moderate in Iran (20); also, a 2009 study by Bahrami showed that a high percentage of EMS centers in Iran did not have enough skilled staff. In another study in Iran demonstrated that the majority of victims in road accidents were dispatched by unskilled technicians (21). Another study in 2014 in Iran by Esmaieli showed that patients' satisfaction was good in all dimensions (ambulance, technician behavior, technician performance, and efficiency of EMS) (22), and a 2012 study by Andero showed that, in New Zealand, satisfaction of patients was high (23).

In this study, patients with low literacy skills expressed more satisfaction than did higher literate patients. Other studies showed that people with low literacy skills don't know their rights and have minimum expectation of EMS $(24,25)$; therefore, the media must make people aware of their rights, especially people with low literacy. As our finding shows, the satisfaction level in males was higher. In other studies, satisfaction level in both sexes was equal $(26,27)$. Of course, another study showed that sex of patients can affect satisfaction level $(28)$. The differences in satisfaction level between both sexes may be due to the absence of female technicians in Iran's EMS, and revision of the organizational chart of EMS to add female technicians may increase patients' satisfaction level. This study found that patients' satisfaction with comfort and equipment inside the ambulance was moderate. A 2007 study by Gland showed that ambulance equipment was improper; they found $74 \%$ of seats in these ambulances were improper for patients. Furthermore, the distance between the technician and patient's bed was not good, and most were improper for service to patients (29). Other studies found that equipment in the selected ambulances were improper for cardiopulmonary resuscitation $(30,31)$. It is necessary for authorities to pay more attention to equipment, airconditioning, height and medical services in ambulances. Study findings indicate that patients had more satisfaction of technicians with a B.Sc. in nursing than other degrees; also a 2011 study by Anderson showed that patients were more satisfied with technicians that have a degree in nursing, and that nurses were able to provide better service to patients (32); another 2009 study by Melisa showed a positive relationship between professional commitment of EMS staffs and their degree (33). Our findings showed that patients were dissatisfied with the performance of technicians. A 2013 study by Krestian showed enough knowledge and skill in their subjects, but that they were not up to date in their information (34). It has been demonstrated that pain and discomfort in respiratory and cardiac patient did not change before and after arriving EMS. But pain and discomfort of orthopedic patients decreased after arriving in EMS. A 2003 study by Kuisma showed a positive correlation between types of disease and satisfaction level of EMS so that patients with cardiac, respiratory, and hypoglycemia had the most satisfaction, and patients with drug toxicity had the least satisfaction of EMS (35). Because the majority of cardiovascular mortality occur in the first four hours after the onset of symptoms in the prehospital phase (36), all EMS staff should be trained for cardiovascular patient management (37). One of the limitations of this study was the differences between universities and EMS units in the various provinces in Iran; thus a country level study is recommended.

\section{Conclusions}

This study showed that patient satisfaction level with EMS, technician performance, and ambulance cabin were moderate and low, but the satisfaction level with technicians was high. Although technicians of EMS had an important role in pain management of orthopedic patients, in pain control of cardiac and respiratory patients, no success was observed. Thus, it is recommended to take correct actions for optimization of ambulance cabins and appropriate education of emergency medical staff about management of cardiac and respiratory patients.

\section{Acknowledgments:}

This study was conducted as a research project approved by the Research Center of Lorestan University of Medical Sciences, Khorramabad, Iran. The approval code was 1783. The authors would like to profusely thank all individuals who supported and helped them to conduct this study.

\section{Conflict of Interest:}

There is no conflict of interest to be declared.

\section{Authors' contributions:}

All authors contributed to this project and article equally. All authors read and approved the final manuscript.

\section{References:}

1) Kazemeini SK, Mohammadi F, Owlia F. Evaluation of satisfaction rate of patients admitted to Yazd Shaheed Sadoughi burn hospital in first nine months of the year 2011. TB. 2013; 11(4): 91-102. 
2) Khoddam H, Joybari L, sanagoo A. Patients' satisfaction of introduced services in clinical educational centers of the Gorgan University of Medical Sciences and its associated factors. J Gorgan Univ Med Sci. $2005 ; 2(1): 13-21$.

3) Institution of Medicine of National Academy. Crossing the Quality Chasm: The IOM health care quality initiative. Available from: http://www.iom.edu/CMS/8089.aspx.

4) Davis BA, Bush HA. Patient satisfaction of emergency nursing care in the United States, Slovenia, and Australia. J Nurs Care Qual. 2003; 18(4): 67-74. doi: 10.1097/00001786-200310000-00004. PMID: 14556583.

5) Bahadori M, Nasiripur A, Tofighi S, Gohari M. Emergency Medical Services in Iran: An Overview. Australasian Medical Journal. 2010; 3(6): 335-9. doi: 10.4066/AMJ.2010.218.

6) Providing Leadership for the Provision of Ambulance Services, The Council of Ambulance Authorities Inc. 2008.

7) Ebrahimian A, Shabanikiya HR, Khalesi N. The role of physiological scores for decision making in internal prehospital emergency situations. Health Med. 2012; 6(11): 3612-5.

8) Ebrahimian AA, Khalesi N, Mohamadi Gh, Tordeh M, Naghipour M. Transportation management in prehospital emergency whit physiological early warning scores. Journal of Health Administration. 2012; 15(49): 7-13.

9) Kouroubali A, Vourvahakis D, Tsiknakis M. Innovative Practices in the Emergency Medical Services in Crete. Proceedings of the 10th International Symposium on Health Information Management Research, ISHIMR. 2005.

10) Naghavi M, Shahraz S, Bhalla K, Jafari N, Pourmalek F, Bartels D, et al. Adverse health outcomes of road traffic injuries in Iran after rapid motorization. Arch Iran Med. 2009; 12(3): 284-94. PMID: 19400607.

11) Mozafari M, Abed-Saidi Z, Pazargadi M, Alavi Majd H. Patients satisfaction measurement in pre-hospital emergency medical services in Iran. ZJRMS. 2012; 13(10): 61.

12) Esmaeili Vardanjani A, Moghadasi J, Rafiei H, Masoudi R, Mohammadi M, Lalegani H, et al. Satisfaction from pre-hospital emergency medical services: a cross sectional study in Shahrekord. J Clin Res Paramed Sci. 2014; 3(2): 103-13.

13) Bahrami MA, Ranjbar Ezzatabadi M, Maleki A, Asqari R, Ahmadi Tehrani Gh. A Survey on the Yazd Prehospital Emergency Medical Services' Performance Assessment, 2009-2010. Research scientific quarterly of health school of Yazd. 2011; 4(30): 45-59.

14) Cummings D, Mc Morris HD. Saskatchewan emergency medical services (EMS) review: inal report. Health ministry. 2009.

15) Members of the Joint Legislative Audit and Review Commission of Virginia. Review of Emergency Medical Services in Virginia. House Document No. 37. Commonwealth of Virginia. 2007.

16) Goodwin K. Emergency medical services in rural America. Published by National Conference of State Legislatures. Washington DC. 2007.

17) Sinclair D. Emergency department crowding, Implications for pediatric emergency medicine. Paediatr Child Health. 2007; 12(6): 491-4. PMID: 19030415, PMCID: PMC2528760.

18) Lau PM, Akbar AK, Fie DY. Service quality: A study of the luxury hotels in Malaysia. Journal of Amarican Academy of Business. 2005; 7(2): 46-56.

19) Matthew T. Evaluating the EMS satisfaction survey of longboat key (florida) fire-rescue. Available from: http://www.irc.dhs.gov/.

20) Swain AH, Al-Salami M, Hoyle SR, Larsen PD. Patient satisfaction and outcome using emergency care practitioners in New Zealand. Emerg Med Australas. 2012; 24(2): 175-80. doi: 10.1111/j.17426723.2011.01525.x. PMID: 22487667.

21) Jafari F, Zayeri F, Johari $Z$. The satisfaction of those who recourse to the to the health centers of Shahid Beheshti university of medical sciences. Daneshvar. 2007; 4(66): 15-22.

22) Khashjan A, Mohammadi R, Tamaddonfar M, Hosseini F. The health service satisfaction of those who recourse to the emergency department. Iran J Nurs. 2006; 18(42): 49-60.

23) Malek-Malekan L, Haghpanah S, Moravvej H, Sharifi H. The effect of intervention in patients' satisfaction of emergency unit in state hospitals at Shiraz. J Jahrom Univ Med Sci. 2010; 3(7): 58-61.

24) Gilad I, Byran E. Ergonomic evaluation of the ambulance interior to reduce paramedic discomfort and posture stress. Hum Factors. 2007; 49(6): 1019-32. doi: 10.1518/001872007X249884. PMID: 18074701.

25) Kim JA, Vogel D, Guimond G, Hostler D, Wang HE, Menegazzi JJ. A randomized, controlled comparison of cardiopulmonary resuscitation performed on the floor and on a moving ambulance stretcher. Prehosp Emerg Care. 2006; 10(1): 68-70. doi: 10.1080/10903120500373108. PMID: 16418093. 
26) Johansson A, Ekwall A, Wihlborg J. Patient satisfaction with ambulance care services: Survey from two districts in southern Sweden. Int Emerg Nurs. 2011; 19(2): 86-9. doi: 10.1016/j.ienj.2010.03.002. PMID: 21459350.

27) Alexander M, Weiss S, Braude D, Ernst AA, Fullerton-Gleason L. The relationship between paramedics' level of education and degree of commitment. Am J Emerg Med. 2009; 27(7): 830-7. doi: 10.1016/j.ajem.2008.06.039. PMID: 19683112.

28) Blomstedt K, Nilsson H, Johansson A. The public's perception of prehospital emergency care in the County of Skane, southern Sweden. Int Emerg Nurs. 2013; 21(2): 136-42. doi: 10.1016/j.ienj.2012.05.004. PMID: 23615522.

29) Kuisma $M$, Määttä $T$, Hakala $T$, Sivula $T$, Nousila-Wiik M. Customer satisfaction measurement in emergency medical services. Acad Emerg Med. 2003; 10(7): 812-5. doi: 10.1111/j.15532712.2003.tb00080.x. PMID: 12837660.

30) Chiriboga D, Yarzebski J, Goldberg RJ, Gore JM, Alpert JS. Temporal trends (1975 through 1990) in the incidence and case-fatality rates of primary ventricular fibrillation complicating acute myocardial infarction: a communitywide perspective. Circulation. 1994; 89(3): 998-1003. doi: 10.1161/01.CIR.89.3.998. PMID: 7880217.

31) Hallstrom AP, Ornato JP, Weisfeldt M, Travers A, Christenson J, McBurnie MA, et al. Public-access defibrillation and survival after out-of-hospital cardiac arrest. N Engl J Med. 2004; 351(7): 637-46. doi: 10.1056/NEJMoa040566. PMID: 15306665. 